\title{
How CAAD is changing society's role in architecture
}

\section{Tom Maver}

Mackintosh School of Architecture, Glasgow School of Art, Glasgow, United Kingdom.

ABSTRACT: It is a modest four decades since the potential for the application of computers to the design of buildings was first realized by a few academics who are still alive. The author is one such! This presentation provides an outline of these four decades but with an emphasis, not on how the technology facilitated the 'production' of the architectural process, more upon the 'product' i.e the quality of the designed artifact. Specifically, the relationship between the objective criteria - cost and performance - and the subjective criteria - aesthetics, cultural significance, etc and on the relationship between design decisions and their consequences.

\section{CONTEXT}

In October 2015, the ACADIA conference was held in Cincinnati, Ohio. Some one hundred plus mostly young people heavily committed to CAAD, attended. Dr Robert Ash presided over a panel discussion ' Pioneers of Design Computation' It featured Don Greenburg arguably the father of computer graphics, Chuck Eastman, arguably the father of BIM and the current author - Tom Maver, who in the mid sixties struggled to develop primitive computer software to predict how design decisions - the geometry and construction of the buildings - might impact on their capital cost, their recurring costs, their energy performance (heat, light sound), their efficiency in pedestrian movement, their evacuation in emergency and in every other aspect of their cost and performance. The one hundred plus people accorded the panel a standing ovation - some welcome recognition that early endeavours were both welcome and worthwhile.

Four decades earlier, the issues were alive yet problematic. Notwithstanding the intellectual aspirations, the computational competence was truly primitive. In order to communicate a 3-D built form to the computer one had, in the lauguage Algol

i) Type in the $X, Y, Z$ coordinates of every vertex.

ii) Identify those coordinates that terminated an edge.

iii) Identify those edges that constituted a surface. iv) Identify those surfaces that constituted a volume.

v) Identify those volumes that constituted a building.

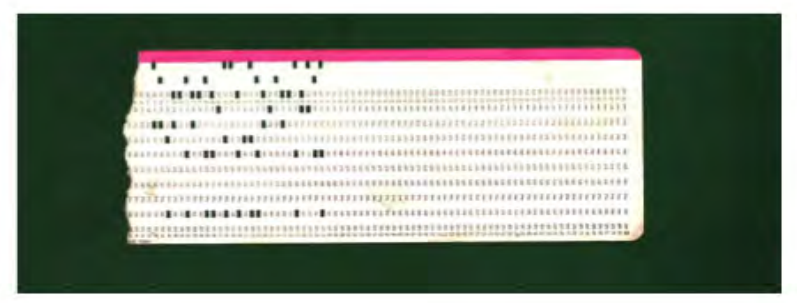

Figure 1 A punched paper card

Figure 1 shows an example of a punched paper card, one of many thousand, required to represent the simplest of buildings. One alternative no less problematic was hundreds of meters of punched paper tape. 


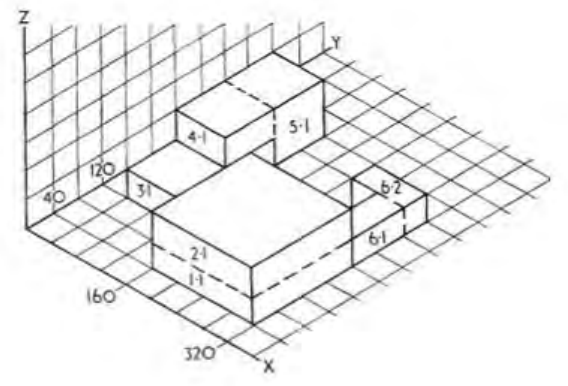

Figure 2 A hand drawn representation of a simple building

Figure 2 shows how a simple built form had to be encoded and Figure 3 shows how a primitive teletype terminal was best able to output representations of plan forms.

\section{ISSUES}

From the earliest and the most primitive steps in CAAD the issues were clear.

The architectural profession had its heart set against CAAD. Whereas architectural students would invite the few pioneers in the field to speak about the emerging techniques, quite frequently tutors would attend to revile the speaker.

The worry was that computers, dealing solely with the measurable characteristics of buildings - capital costs, recurring costs, heat, light and sound, movement - failed to address the non - measurable characteristics - most importantly the aesthetics of the building and its culture significance. The consequence, so the profession believed, would be souless'boxes'

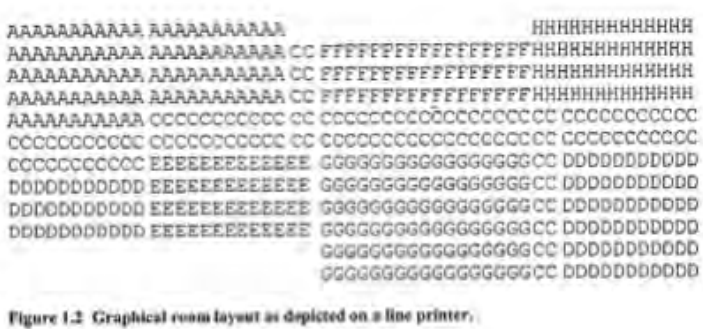

Figure 3 An example of teletype output for a floor plan.

Those struggling to develop the technology took a different view. The argument (one that was poorly articulated) was that the ability to predict the myriad objective characteristics provided a knowledge base that could inform judgements on the subjective characteristics. The degree to which this is the case is addressed in the concluding part of this paper.

\section{EVOLUTION OF TECHNOLOGY.}

The research group set up by the author at the University of Strathclyde in 1969 - the Architecture and Building Aids Computer Unit, Strathclyde (ABACUS) - was one of a handful in Europe and North America to wrestle with the primitive computer tools available at that time and progressively contribute to the development of the hardware and software that is now known within the broad field of Information and Communication Technology (ICT) as Computer Aided Architectural Design (CAAD)

In ABACUS the thrust of the software development was driven by a seemingly simple 
to a physical prototype - on which design refinements could be applied.

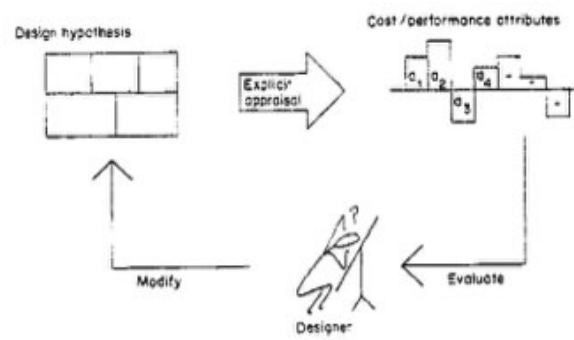

Figure 4 The initial concept for the first appraisal of buildings.

in which a design for the building - its geometry, construction and location- was described to the computer. A set of algorithms, based on the laws of physics and economics would then be applied to the design as it was subjected to the vagaries of yearly climate and functional usage. The output would be the histogram of the consequential cost and performance characteristics - capital costs, recurring costs (for heating, lighting, maintenance) energy consumption (heat and light) etc; ie all that could be measured with an acceptable degree of accuracy. This histogram and how it varied with changes to the design hypothesis, would (certainly could) inform the direction of the evolution of the design exploration.

The deceptive complexity of this view of the design activity is that the relationship (particularly the rate of change) between the wide set of cost/performance variables is highly dynamic. For example, changing the area of glazing, say, to the south façade of the building alters virtually all the cost/ performance characteristics. This relationship is a priori unknown and can only be discovered as the explicit design investigation is explored.

Although the expression was not applied at the time (circa 1970), it is now clear that what was being created was a virtual prototype - as opposed
The earliest publication of an account of the application of such a virtual prototype, deploying the most primitive computer technology (pre graphics, pre online etc) was entitled PACE: a Package for Architectural Computer Evaluation (Maver 1972)

The difficult though rapid evolution from PACE to the current state of the art, over the exciting four decades, has yet to be properly recorded. However, at the ACADIA Conference in Cincinnati in October 2015, the panel session 'Pioneer of Design Computation' (Maver 2015) brought a standing ovation from the $100+$ audience of mostly young people and, more importantly a commitment to tell the story in order to extrapolate the future.

None the less, the key development can be summarised as follows.

- The evaluation of 'back and white' (actually green and yellow) computer graphics introduced by the US company; TEKTRONIX in its iconic 4010 terminal changes to a simple plan form requires the image to be erased and then redrawn.

- Encoding of the laws of perspective geometry to allow representation of 3D 'wireline' views of buildings and the subsequent development in BIBLE (Building with Invisible Back Lines Eliminated)

Introduction of colour graphics to allow the first (embarrassingly crude) colour images of buildings.

- Visual Impact Analysis of constructions in the urban or rural landscape. The representation of alternative electricity transmission routes has moved from an innovative $\mathrm{PhD}$ thesis to software free on most PCs. 
The advancement in scale from the representation of individual buildings to the entire city scapes (Maver 1987)

- Animation: the change from stop - frame film - based technologies, set up to run all night, to real time dynamic inter - action.

- The huge increase in the sophistication of the modelling of the dynamic thermofluid behaviour of building as they respond hourly and annually to weather and climate (Clarke \& Maver1991)

- The application of multimedia software that help to explain our built cultural patrimony

- The evolution is of virtual reality and virtual worlds.

One measure of this evolution can be seen in the expansion of the company Integrated Environmental Solutions (IES) formerly known as then a moderately sized spin - out company - as ABACUS Simulations Limited. IES, providing CAAD Consultancy to architectural and engineering practices, now has some 150 employees based in offices in four continents.

Facilitate the expression of the user in the design decision making process.

The author persuaded the UK (then) Social Sciences Research Council (SSRC) to fund a study involving Nursery school Teachers in the design of a modestly sized school for which there are already was standard professionally designed and existing options. The ABACUS team developed the Partial (PARTicipation In Architectural Layout) suite of relatively simple computer programmes based on the Tectronix 4010 Graphics terminal. Partial 1 allowed the research team to define the design problem (the brief). Partial 2 allowed some $20+$ teachers to create a single storey geometry and construction (with feedback) while Partial 3 recorded the design history of each participants design progression. Elaborate histories, both graphic and auditory, were catalogued (Smith \& Watts 1979).

\section{DESIGN PARTICIPATION}

Despite the thrilling advances in ICT and CAAD the fundament issue remains: how to deal with the value judgments that surround the subjective matters of aesthetics and cultural significance. After four decades of rapid development, the view of the author is un - altered: our ability to predict the objective characteristics provides the basis to inform the value judgements of the subjective characteristics. The question is whose value judgements?

Such was the confidence of at least one of the pioneers and a few far-sighted research fellows that, in the longer term at least, the capability of the users of buildings, powered by increasingly intuitive CAAD software, would allow design participation. That to say: not replace the design skills of the professional architect/ engineer, but

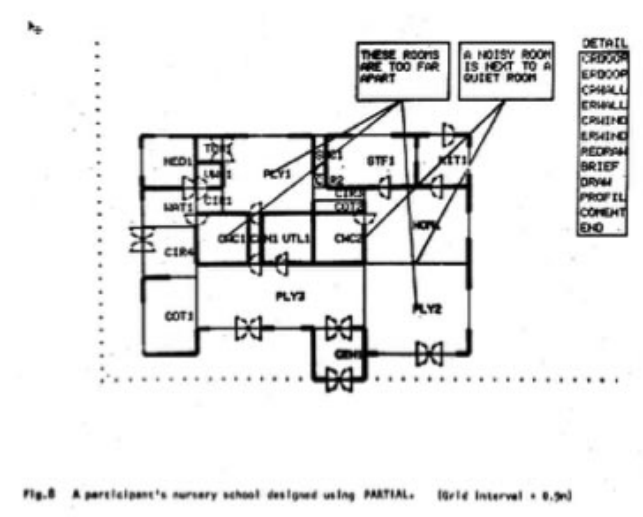

Figure 5 The Interface that Partial presented.

Figures $5 \& 6$ illustrate stages in the evolution (and feedback) of one participant's design exploration. 


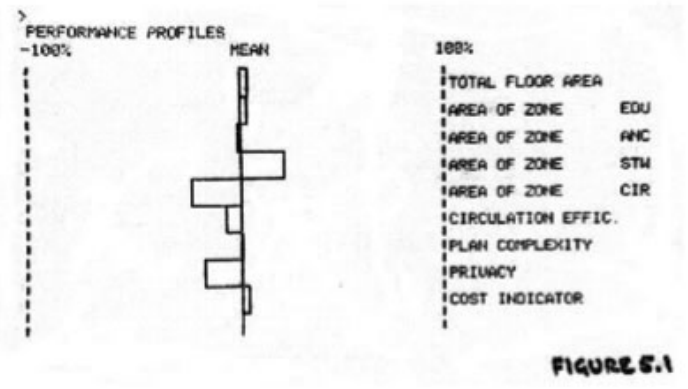

Figure 6 The simple feedback to nursery teachers.

The research team was sufficiently encouraged by the fact that each and every nursery school teacher produced a feasible design within the pre - set constraint to go on to form teams of teachers who were then tasked with working towards a design that represented the best possible compromise amongst the individual design options. Without exception, despite initially favouring their own design, the member of each design team found a composite scheme that all participants marked above their own individual scheme.

The team then conducted two important controlled evaluations, with the following results.

i. When presented with a number of design options, architectural tutors were unable to distinguish the design quality between those designs created by professional architects and those collaboratively created by nursery school teachers.

ii. When (presented with the same set of options, nursery school teachers in another city wholly unaware of the background to the test, universally ranked all the scheme designed by the teacher above those of the professionals.
The final report to the SSRC captured the research team's thrill at these results. Regrettably, the SSRC review committee deemed the work to be too interventionist and declined to support if further.

\section{CONCLUSIONS AND THE WAY FORWARD.}

It is undeniable that the rate and scale of development of ICT and CAAD specifically, over the last four decades has been quite extraordinary, but what of the issues?

Surely the concern that the application of computers would somehow result in all buildings ending up as boring boxes has well and truly been dispelled. Indeed, there is over-whelming evidence that our ability to 'test' design options, has promoted design innovation thereby increased variety in design solutions. A significant number of recently constructed and revered buildings could not have been designed and built without the application of computers.

This would suggest that the aesthetic and cultural characteristics, far from being neglected, are at the forefront of design thinking and that value judgements are, indeed, being given the attention they demand and deserve.

But whose value judgements? In section 4 of this paper, considerable evidence is presented to show that, in a relatively simple building type, the users can make seemingly positive contributions to the design evolution.

It is not suggested that this contribution in any sense supplants the expertise of the professional architect, but it is suggested that involvement in the design process, supported by the appropriate computer tools, allow the value judgments of user participation in building design is one of society's most important challenges. 
The author gratefully acknowledges the contribution made by over 100 young people who came and went as research students and fellows, in the 40 years of the existence of ABACUS. He also thanks his current employee - The Mackintosh School of Architecture, Glasgow School of Art for its moral and financial support in presenting this work.

\section{REFERENCES.}

Maver, T. 1972. PACE1: An On-Line Design Facility. Proceedings of the EDRA 3/ARB Conference, Los Angeles, USA
Maver, T., Greenberg,D., Eastman,C. 2015. Panel Discussion "Pioneers of Design Computation" at the ACADA Conference, Cincinnatti, USA

Maver, T. 1987. Flying Dreams: Visualization and Animations in Architecture. Proceedings of Computer Graphics 87, London

Clarke, J, Maver,T. 1991. Advanced Design Tools for Energy Conscious Building Design. Building Environment, Volume 26, No 1.

Smith,M \&Watts, J 1979. Furthre developments of a participatory computer based design tool. ABACUS Occasional Paper 73, University of Strathclyde. 